\title{
ADDENDUM TO: MUTATION BREEDING OF DAHLIA VARIABILIS
}

\author{
C. BROERTJES and J. M. BALLEGO
}

\author{
Association Euratom - ITAL, Wageningen, The Netherlands \\ Fa. Ballego en Zonen, Leiden, The Netherlands
}

Received 15 , January, 1968

Referring to our article 'Mutation breeding of Dahlia variabilis' which appeared in Euphytica 16 (1967): 171-176, it is now reported that five radiation-induced mutants of the cv. Arthur Godfrey, a decorative dahlia with flaming red-orange flowers of good form and habit, have been commercialized in 1967, viz:.

Autumn Harmony: cadmium-orange with scarlet centre.

Explosion: blood-red with bright yellow centre; massive bloom, full at centre and having a very fine habit.

Holland Jubilee: light orange throughout; bloom firmer and more regular than the original cultivar.

Progression: brick red throughout.

Rosy Mist: empire rose throughout.

All mutants have a similar size bloom as cv. Arthur Godfrey. A purple flowering as well as a scarlet-red mutant will probably be commercialized in 1968 when enough material has been grown.

In a joint programme by the private plant breeding firm K. Maarse Dzn Jr at Aalsmeer and the Association Euratom-ITAL, irradiation of the dahlia cultivar Authority resulted in a mutant, sold under the name The Governor.

Authority is a medium-cactus dahlia with bronzy-salmon flowers, $18 \mathrm{~cm}$ diameter. The plant grows $1.50 \mathrm{~m}$ high.

The radiation-induced mutant The Governor has a deep copper-red flower; other characters are unchanged. It was constant in colour over three years of observation. 